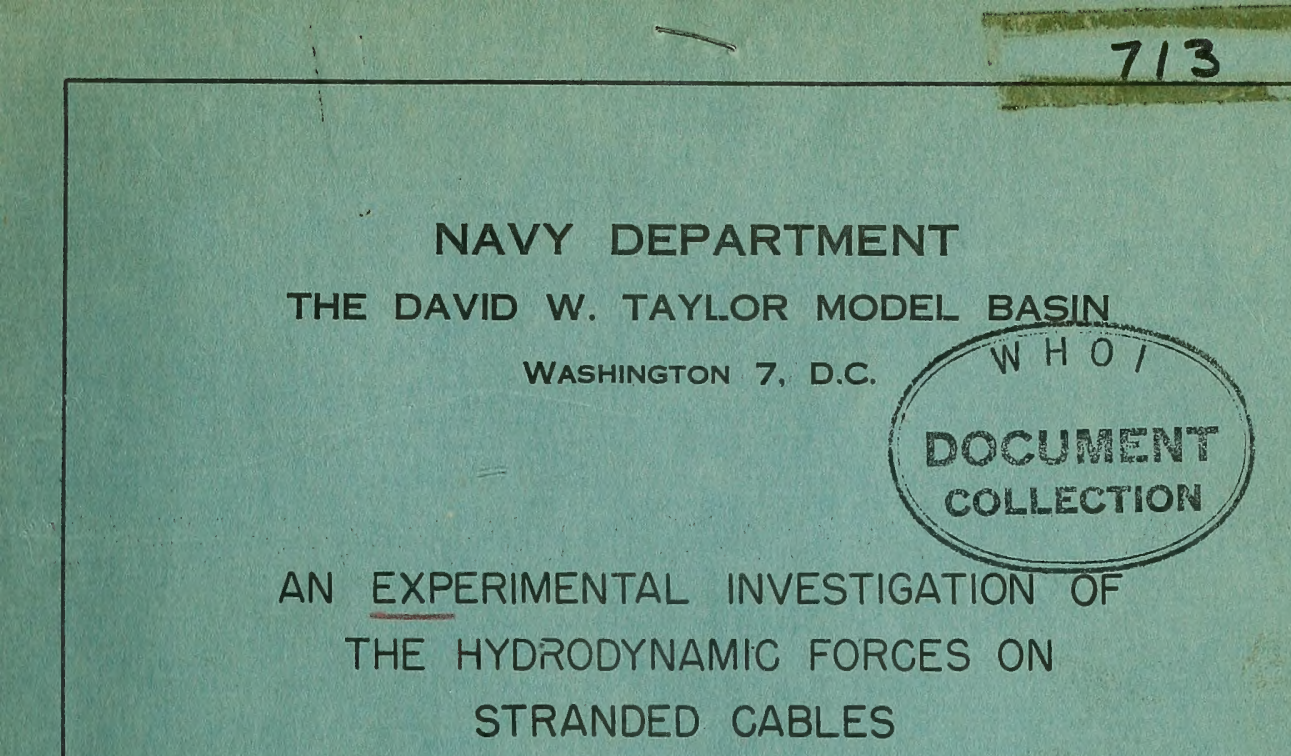

by

Leonard Pode

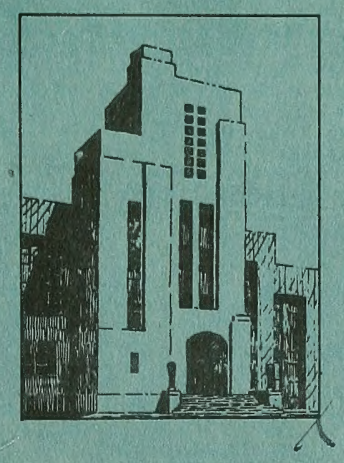

May 1950

Report 713

NS $880-018$ 


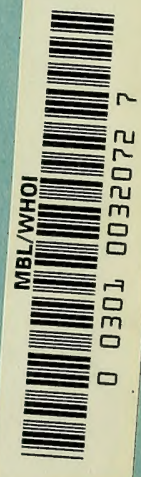




\section{INITIAL DISTRIBUTION}

Copies

Chief, BuShips, Project Records (Code 362) for distribution:

5 Project Records

1 Technical Assistant to Chief of the Bureau (Code 106)

1 Research (Code 330)

1 Technical Information Disclosure (Code 367) for: National Research Establishment, Halifax, Canada Attn: Mr. Richard Parr Blake

1 Minesweeping (Code 620)

1 Magnetic Defense (Code 660M)

2 Commanding Officer and Director, U.S. Navy Electronics Laboratory, Point Loma, San Diego 52, Calif.

1 Commanding officer and Director, U.S. Navy Underwater Sound Laboratory, Fort Trumbull, New London, Conn.

1 Commander, Puget Sound Naval Shipyard, Bremerton, Wash.

1 Development Contract Officer, Kellex Corporation, Silver Spring Laboratory, 936 Wayne Ave., Silver Spring, Md.

1 Director, Woods Hole Oceanographic Institution, Woods Hole, Mass.

1 U.S. Dept. of Interior, Geological Survey, Equipment Development Laboratory, 1509 Hess St., Columbus 12, Oh10.

Attn: A.H. Frazier 

SMMBOLS .

$\phi \quad$ Angle between the cable and the stream

$x$ Coordinate in $\vec{i}$ direction

$y$ Coordinate in $\vec{j}$ direction

$z$ Coordinate in $\vec{k}$ direction

$\vec{i}$ Unit vector in the direction of the stream

$\vec{j}$ Unit vector in the direction of gravity

$\vec{k}$ Unit vector normal to $\vec{i}$ and $\vec{j}$; i.e., $\vec{k}=\vec{i} \times \vec{j}$

$\overrightarrow{1}$ Unit vector in the direction of the cable

$\vec{s}$ Unit vector normal to the cable and the stream

$\vec{n}$ Unit vector normal to $\vec{f}$ and $\vec{s}$

F Component of the hydrodynamic force per unit length of the cable in the direction; referred to as the tangential force

S Component of the hydrodynamic force per unit length of the cable in the $\vec{s}$ direction; referred to as the side force

$\mathrm{N}$ Component of the hydrodymamic force per unit length of the cable in the $\vec{n}$ direction; referred to as the normal force

$\mathrm{C}_{\mathrm{f}}$ Coefficient of the tangential force;

$$
C_{f}=\frac{F}{\frac{1}{2} \rho U^{2} d}
$$

$\mathrm{C}_{\mathrm{S}}$ Coefficient of the side force;

$$
C_{S}=\frac{S}{\frac{1}{2} \rho U^{2} d}
$$

$c_{n}$ Coefficient of the normal force;

$$
C_{n}=\frac{N}{\frac{1}{2} \rho U^{2} d}
$$

$C_{n}$ The value of $C_{n}$ for $\phi$ equals 90 degrees; also the proportionality factor between $C_{n}$ and $\sin ^{2} \phi$

$\rho$ Density of water

$U$ Speed of the stream

d Diameter of the cable

$l$ Direction cosine of the cable in the $\overrightarrow{1}$ direction;

$$
\vec{i} \cdot \vec{i}
$$

$m$ Direction cosine of the cable in the $\vec{J}$ direction; $m=\vec{j} \cdot \vec{i}$

$n$ Direction cosine of the cable in the $\vec{k}$ direction; $n=\vec{k} \cdot \vec{i}$ 
D Total drag of the cable

I Length of the cable

$\delta$ Drag per unit length of the cable;

$$
\delta=\frac{D}{L}
$$

w The weight in water per unit length of the cable

$w_{f}$ Component of the weight in water per unit length of the cable in the $\vec{f}$ direction

$\mathrm{w}_{\mathrm{S}}$ Component of the weight in water per unit length of the cable in the $\vec{s}$ direction

$w_{n}$ Component of the weight in water per unit length of the cable in the $\vec{n}$ direction 
AN EXPERTMENTAL INVESTIGATION OF THE HYDRODYNAMIC FORCES

ON STRANDED CABLES

by

Leonard Pode

\section{ABSTRACT}

Experimental evidence verifies the sine-square law for the normal component of the hydrodynamic force acting on stranded cables. The side component appears to be proportional to the sine of the angle of inclination of the cable to the stream for very small angles, attaining a maximum value at an angle that depends upon the size and construction of the cable.

\section{INTRODUCTION}

During the summer and fall of 1945 a series of experiments was conducted at the David Taylor Model Basin by Alice E. MacDonald and Dr. M.A. Garstens, to determine the angle of tow and to measure the forces acting upon freely trailed stranded cables. The purpose of these experiments was to study the relationship between the hydrodynamic forces acting on cables and the angle of tow; the main interest being the investigation of this relationship when the angle of the cable to the stream is small, 1.e., less than ten degrees. Although the results of the original analysis of the data were obscure, these results indicated a marked deviation from the sine-squared law for the component of the hydrodynamic force acting normal to the cable and lying in the plane including the directions of the cable and the stream. However, a subsequent analysis, made in the summer of 1947 , by the writer, together with William E. Cummins, led to significant results which accounted for the apparent discrepancy.

Eight samples of cable were tested, four of 1/16-inch diameter, three of 1/8-inch diameter and one of 1/4-inch diameter (see Table 1 ).

\section{THEORY OF THE EXPERIMENTAL METHOD}

The basis of the experimental method rests on the theory that a freeIy towed flexible cable will assume the configuration of a straight line and that this line will be inclined at such an angle that the component of the resultant force that is normal to the cable vanishes. If end effects are 
negligible, and both the cable and the stream are uniform-so that each element of the cable has the same equilibrium position, it is clear that the configuration of the cable must be such a straight line. The external forces acting upon the cable are: 1) The hydrodynamic force and 2) the weight of the cable in water. If the direction of the cable is measured and the weight of the cable is known, the components of the hydrodynamic force that are normal to the cable can be found, since these must balance the corresponding components of the weight of the cable. Thus the cable acts as a balance, welghIng the normal components of the hydrodynamic force. Unfortunately, the weight of the cable is fixed so that the only method of changing the angle of the cable is to vary the speed of the stream. Hence, it is an inevitable consequence of this method that the force acting upon the cable at each angle of the cable to the stream is investigated at a different Reymolds number.

The component of the hydrodynamic force that is parallel to the cable can be determined through a knowledge of the tension in the cable at the upper end. This tension can in tum best be found by measuring the drag of the cable.

The problem of choice of axes requires some attention. There are three directions that are intrinsically involved in the physical situation: 1) The direction of the stream, 2) the direction of gravity, and 3) the direction of the cable. Since stranded cables assume an angle of yaw when freely trailed these three directions will not be coplanar. The direction of the stream and the direction of gravity are of course perpendicular and the most convenient fixed reference frame, for the purpose of making measurements, is the set of these two directions and their mutual perpendicular. Thus, let $x, y$, and $z$ represent displacements and $\vec{i}, \vec{j}, \vec{k}$ represent unit vectors respectively in the direction of the stream, in the direction of gravity and in the direction of the mutual perpendicular-which is chosen so as to complete a set of right-handed rectangular Cartesian axes. Call this system Reference Frame I.

When studying the hydrodynamic force acting upon the cable it must be remembered that in so far as the hydrodynamic situation is concemed the direction of gravity is entirely extraneous. The only directions that can affect the hydrodynamic force are the directions of the stream and the direction of the cable. The hydrodynamic forces should be related to the angle, $\phi$, between these two directions and any error of relating the hydrodynamic force to the projection of this angle of the cable in the $x-y$ plane must be avoided. For the purpose of resolving the hydrodynamic force into components in a meaningful way a new reference frame is needed. Such a reference frame is formed in the following manner: Let $\vec{f}$ be a unit vector in the direction of the cable. 
Then $\vec{s}=\frac{(\vec{i} \times \vec{f})}{\sin \phi}$ is a unit vector normal to both the cable and the stream, and $\overrightarrow{\mathrm{n}}=\overrightarrow{\mathrm{f}} \times \overrightarrow{\mathrm{s}}$ is a unit vector that is normal to the cable, lying in the plane that includes the direction of the cable and the direction of the stream. The three unit vectors $\vec{f}, \vec{s}$, and $\vec{n}$ then define a rectangular Cartesian reference frame which shall be called Reference Frame II. When the hydrodynamic force acting on a unit length of cable is resolved in this reference frame the components $\mathrm{W} 111$ be designated $\mathrm{F}, \mathrm{S}$, and $\mathrm{N}$ respectively.

It is the component $\mathbb{N}$ with which the sine-squared law has been associated. The main hypothesis which is being investigated here is that the coefficient $C_{n}=\frac{N}{\frac{1}{2} \rho U^{2} d}$, (where $\rho$ is the density of the water, $U$ the speed of the stream and $d$ the diameter of the cable) may be written $C_{n}=C_{r} \sin ^{2} \phi$. where $C_{r}$ does not vary with $\phi$.

The component $S$ is zero for a smooth round cable or for any cable that presents a symmetrical profile to the stream. The fact that a stranded cable does not present a symmetrical profile is apparent from Figure 1 , which shows the cross-section of a stranded cable in an inclined plane. It is the existence of this $S$ component which is responsible both for the yawing of stranded cables and for the fact that stranded cables often tow closer to the surface of the water than smooth round cables of the same diameter and welght.

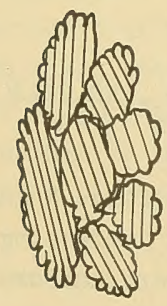

Figure 1 - Profile of a Stranded Cable

This sketch shows the asymetrical profile of a $1 / 8$-1nch stranded cable of $7 \times 19$ construction which is cut in a plane that 1 s inclined at an angle to the axis of the cable. 
If the cable has the direction cosines $l, m, n(l=\cos \phi)$ in $\operatorname{Ref}-$ erence Frame $I$, the unit vectors of Reference Frame II may be written

$$
\begin{gathered}
\vec{f}=\overrightarrow{l i}+m \vec{j}+n \vec{k} \\
\vec{s}=\frac{\vec{i} \times \vec{f}}{\sin \phi}=\frac{-n \vec{j}+m \vec{k}}{\sin \phi} \\
\vec{n}=\frac{\vec{f} \times(\vec{i} \times \vec{f})}{\sin \phi}=\frac{\vec{i}-\vec{f} \cdot \overrightarrow{i f}}{\sin \phi}=\frac{\left(1-l^{2}\right) \vec{i}-\ln \vec{j}-\ln \vec{k}}{\sin \phi}
\end{gathered}
$$

Let the weight in water per unit length of the cable be of magnitude $w$. Since the weight of the cable acts in the $\vec{j}$ direction the components of the weight in Reference Frame II are respectively

$$
\begin{gathered}
w_{f}=w \vec{j} \cdot \vec{f}=w m \\
w_{s}=w \vec{j} \cdot \vec{s}=\frac{-w n}{\sin \phi}=-w n \csc \phi \\
w_{n}=w \vec{j} \cdot \vec{n}=\frac{-w l m}{\sin \phi}=-w m \cot \phi
\end{gathered}
$$

The equilibrium of forces normal to the cable requires

$$
\begin{aligned}
& \mathrm{S}=w n \csc \phi \\
& \mathrm{N}=\mathrm{w} m \cot \phi
\end{aligned}
$$

so that

$$
C_{S}=\frac{S}{\frac{1}{2} \rho U^{2} d}=\frac{w n \csc \phi}{\frac{1}{2} \rho U^{2} d}
$$

and

$$
C_{n}=\frac{N}{\frac{1}{2} \rho U^{2} d}=\frac{w m \cot \phi}{\frac{1}{2} \rho U^{2} d}
$$

The component of the hydrodynamic force $F$ and the $\mathrm{w}_{f}$ component of the we1ght do not cancel but are additive in increasing the tension in the cable. Since the forces acting upon the cable are uniform along the cable, the tension at the upper end may be written

$$
T=\left(F+w_{f}\right) L=(F+w m) L
$$

where $L$ is the length of the cable. Also, $T=D \sec \phi$, where $D$ is the drag of the cable, so that $(F+w m) L=D \sec \phi$ and

$$
F=\frac{D}{L} \sec \phi-w m=\delta \sec \phi-w m,
$$


hence,

$$
C_{f}=\frac{F}{\frac{1}{2} \rho U^{2} \mathrm{~d}}=\frac{\delta \sec \phi-w m}{\frac{1}{2} \rho U^{2} \mathrm{~d}}
$$

where $\delta=\frac{D}{I}$ is the drag per unit length of the cable. In measuring $\delta$, tare drags and end and surface effects must be eliminated.

Using Equations [7], [8], and [10], the hydrodynamic force acting on the cable can be calculated from measured values of $w, \delta$, and the direction of the cable.

\section{EXPERIMENTAL TECHNIQUE}

To determine the direction cosines of the lines assumed by the cables, the cables were towed in the deep-water basin. The tow point was placed one inch above the surface of the water at a forward position on the carriage. The cables were free to turn about a vertical axis through the tow point but could not spin about their own axis. Two optical instruments were used, a traveling telescope and a transit, both of which were mounted towards the rear of the carriage about forty feet from the tow point, see Figure 2. The telescope travelled along a level path at a known angle to the direction of the stream and was mounted so as to sight always in the direction of gravity. The relative positions of the tow point and the path of the telescope were measured. Then the determination of the exact position of the telescope when the telescope was directly above the cable enabled the calculation of the projected angle of the cable in the $\mathrm{x}-\mathrm{z}$ plane, i.e., the angle of yaw. The transit was mounted in a fixed position so as to sight always in a plane perpendicular to the direction of the stream. The distance of the tow point from this plane and the position of the transit relative to the tow point were measured. This permitted the determination of the depth of the cable at the plane of the transit, by a simple triangulation which took into account the angle of yaw and the refraction of light at the water surface. All the information required to compute the direction cosines of the line of the cable was thus provided. In this manner, the direction of each cable at various speeds was measured.

In a separate series of runs, the cables were towed from the drag dynamometer and the drag forces acting on the cables were measured by standard methods.

\section{EXPERINENTAL RESULTS}

The pertinent facts regarding the cables that were test 1 are listed in Table 1 . 
All the data in Table 1, except that listed in Column (7), are original data taken in 7945 . It is believed that at that time the cables were

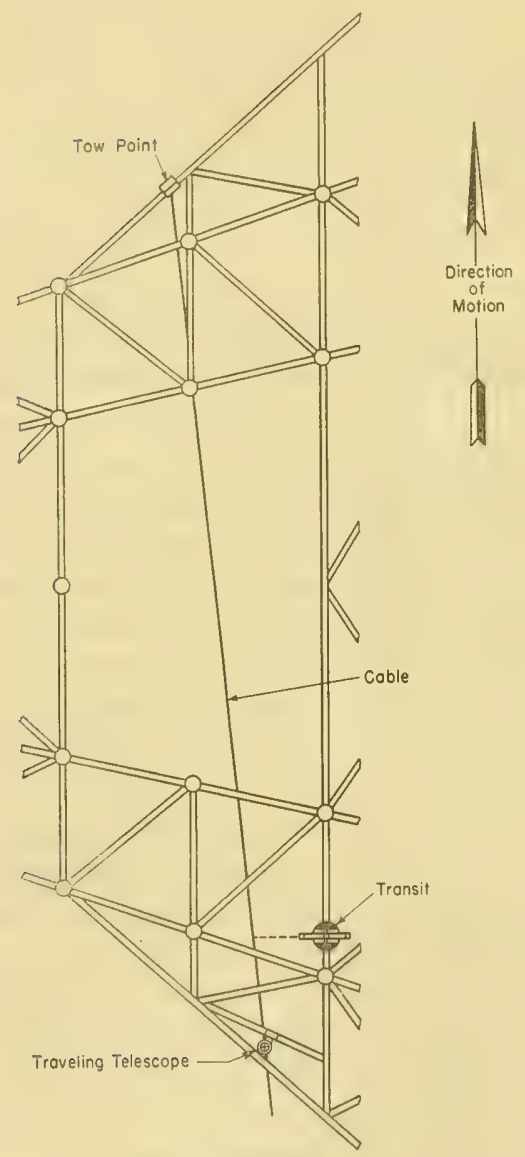

Figure 2q - Overheed View of Towing and Sighting Arrangement weighed with a spring scale and apparently no correction was made to obtain: the weight in water. The cables designated $A, D, E, F$, and $G$ were found in 1947 and reweighed on a sensitive balance while the cables were immersed in the basin water. These welghts per unit length so found are listed in Column (7). The cables $B, C$, and $H$ could not be found. The entries for them in Column (5) were obtained by measuring a sample of cable obtained from stock which fitted the description of these cables.

The measurement of the direction cosines of the cable and the pertinent values obtained therefrom are tabulated in Table 2 .

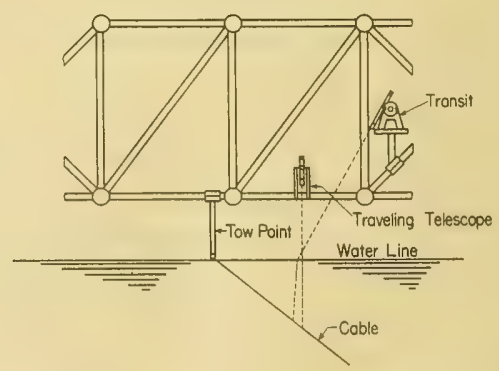

F1gure $2 b$ - V1ew of Towing and Sighting Arrangement from the Rear

Figure 2 - Technique of Measuring Cable Angles 
TABLE 1 - L1st of Cables Tested

\begin{tabular}{|c|c|c|c|c|c|c|}
\hline $\begin{array}{c}\text { (1) } \\
\text { Desig- } \\
\text { nation }\end{array}$ & $\begin{array}{c}\text { (2) } \\
\text { Diameter } \\
\text { inches }\end{array}$ & $\begin{array}{c}\text { Length } \\
\text { feet }\end{array}$ & Lay & $\begin{array}{c}\text { (3) } \\
\text { Weight } \\
\text { pounds }\end{array}$ & $\begin{array}{c}\text { We1ght per Unit } \\
\text { Length } \\
\text { pounds per foot }\end{array}$ & $\begin{array}{c}\text { (7) } \\
\text { We1ght per Unit } \\
\text { Length in Water } \\
\text { pounds per foot }\end{array}$ \\
\hline A & $1 / 16$ & 61.65 & $\begin{array}{c}19 \text { wire } \\
\text { strand }\end{array}$ & 0.047 & 0.0076 & 0.00679 \\
B & $1 / 16$ & 61.05 & $7 \times 7$ & 0.0446 & 0.0073 & $0.00638^{*}$ \\
C & $1 / 16$ & 60.27 & $7 \times 7$ & 0.0446 & 0.0074 & $0.00638^{*}$ \\
D* & $1 / 16$ & 53.73 & $7 \times 7$ & 0.0436 & 0.0081 & 0.00693 \\
E & $1 / 8$ & 63.20 & $7 \times 7$ & 1.696 & 0.0268 & 0.0223 \\
F & $1 / 8$ & 59.79 & $7 \times 19$ & 1.746 & 0.0292 & 0.0249 \\
G & $1 / 8$ & 61.08 & $7 \times 19$ & 1.916 & 0.0314 & 0.0268 \\
H & $1 / 4$ & 53.58 & $7 \times 19$ & 5.586 & 0.1042 & $0.0889 *$ \\
\hline
\end{tabular}

Some of the data tabulated in Table 2 are presented graphically in Figures 3 and 4. The lines shown in Figure 3 are drawn at the average values of $\frac{C_{n}}{\sin ^{2} \phi}$. These average values are measures of $C_{r}$ and are tabulated below in Table 3.

Because this reanalysis of the experiments was undertaken such a long time after the original data were obtained there are naturally some questions regarding the data, which, in the absence of the personnel who originally conducted the experiments, could not be clarified. To begin with, the original figures for the weights of the cable in water could not be considered reliable and some doubt must be cast on the accuracy of the reweighings, since the reweighings were made two years afterward, the cables having suffered some corrosion in the interim.* It will be noted from Equations [7] and [8], however, that an error in $w$ only introduces a constant-percentage error in $C_{n}$ and $\mathrm{C}_{\mathrm{S}}$, so that the manner in which these coefficients vary is not affected. In particular, if $\frac{C_{n}}{\sin ^{2} \phi}$ is independent of $\phi$ an error in will not affect this relationship.

An error of smaller magnitude but of a more serious nature may be present in the determination of the direction of the cable. Inasmuch as the direction of the cable is measured by means of a fixed transit and a telescope travelling in a fixed path, it is apparent that any error in the geometry of

*The drying and chipping of the paint on the cable designated "D" make the weight of this cable particularly uncertain. 
TABLE 2 - Cable Angles and Force Coefficients

\begin{tabular}{|c|c|c|c|c|c|c|c|c|c|c|c|}
\hline $\begin{array}{l}\text { Speed } \\
\text { knots }\end{array}$ & $l$ & II & $\mathrm{n}$ & $c_{n}$ & $\sin ^{2} \phi$ & $\mathrm{c}_{\mathrm{s}}$ & Bin $\phi$ & $\phi$ & $\frac{c_{n}}{\sin ^{2} \phi}$ & $0^{*}$ & $\mathrm{c}_{\mathrm{f}}$ \\
\hline \multicolumn{12}{|c|}{ Cable A $-1 / 16$ 1nch } \\
\hline 4.00 & 0.99035 & 0.1385 & 0.00446 & 0.0293 & 0.0192 & 0.00095 & 0.1386 & 7.97 & 1.53 & 0.008 & 0.031 \\
\hline 5.00 & 0.99420 & 0.7074 & 0.00716 & 0.0188 & 0.0116 & 0.00126 & 0.1076 & 6.18 & 1.62 & 0.011 & 0.029 \\
\hline 5.98 & 0.99635 & 0.0850 & 0.00768 & 0.0131 & 0.00729 & 0.00119 & 0.0854 & 4.90 & 1.80 & 0.015 & 0.028 \\
\hline 7.00 & 0.99733 & 0.0724 & 0.00984 & 0.00956 & 0.00533 & 0.00130 & 0.0730 & 4.19 & 1.79 & 0.019 & 0.026 \\
\hline 8.02 & 0.99809 & 0.0596 & 0.01627 & 0.00708 & 0.00382 & 0.00194 & 0.0618 & 3.54 & 1.85 & 0.025 & 0.027 \\
\hline 9.02 & 0.99863 & 0.0490 & 0.01864 & 0.00544 & 0.00274 & 0.00207 & 0.0523 & 3.00 & 1.99 & 0.031 & 0.026 \\
\hline 9.98 & 0.99898 & 0.0413 & 0.01806 & 0.00434 & 0.00204 & 0.00190 & 0.0452 & 2.59 & 2.13 & 0.037 & 0.026 \\
\hline \multicolumn{12}{|c|}{ Cable B - 1/16 1nch } \\
\hline 3.01 & 0.98656 & 0.1628 & 0.0141 & 0.0483 & 0.0267 & 0.00424 & 0.1634 & 9.40 & 1.81 & 0.007 & 0.047 \\
\hline 4.02 & 0.99227 & 0.1231 & 0.0158 & 0.0271 & 0.0154 & 0.00350 & 0.1241 & 7.13 & 1.76 & 0.009 & 0.036 \\
\hline 5.03 & 0.99476 & 0.0982 & 0.0280 & 0.0168 & 0.0105 & 0.00482 & 0.1022 & 5.87 & 1.60 & 0.013 & 0.034 \\
\hline 6.00 & 0.99598 & 0.0794 & 0.0412 & 0.0109 & 0.00802 & 0.00568 & 0.0896 & 5.14 & 1.36 & 0.017 & 0.032 \\
\hline 7.03 & 0.99723 & 0.0622 & 0.0407 & 0.00750 & 0.00553 & 0.00492 & 0.0744 & 4.27 & 1.36 & 0.022 & 0.031 \\
\hline 8.04 & 0.99812 & 0.0478 & 0.0382 & 0.00536 & 0.00376 & 0.00429 & 0.0613 & 3.51 & 1.43 & 0.028 & 0.030 \\
\hline 9.03 & 0.99865 & 0.0393 & 0.0341 & 0.00412 & 0.00270 & 0.00358 & 0.0519 & 2.98 & 1.53 & 0.034 & 0.029 \\
\hline 9.99 & 0.99904 & 0.0319 & 0.0302 & 0.00324 & 0.00192 & 0.00307 & 0.0438 & 2.51 & 1.69 & 0.041 & 0.029 \\
\hline \multicolumn{12}{|c|}{ Cable $c-1 / 16$ inch } \\
\hline 4.00 & 0.99125 & 0.1315 & 0.0117 & 0.0275 & 0.0174 & 0.00246 & 0.1320 & 7.59 & 1.58 & 0.009 & 0.036 \\
\hline 5.02 & 0.99414 & 0.1052 & 0.0243 & 0.0171 & 0.0117 & 0.00397 & 0.1081 & 6.21 & 1.46 & 0.012 & 0.032 \\
\hline 6.00 & 0.99592 & 0.0826 & 0.0365 & 0.0113 & 0.00814 & 0.00500 & 0.0902 & 5.18 & 1.39 & 0.015 & 0.028 \\
\hline 6.01 & 0.99581 & 0.0842 & 0.0355 & 0.0113 & 0.00836 & 0.00478 & 0.0914 & 5.25 & 1.35 & 0.015 & 0.028 \\
\hline 7.04 & 0.99711 & 0.0668 & 0.0361 & 0.00786 & 0.00577 & 0.00426 & 0.0760 & 4.36 & 1.36 & 0.021 & 0.029 \\
\hline 7.98 & 0.99874 & 0.0503 & 0.0346 & 0.00575 & 0.00372 & 0.00396 & 0.0610 & 3.50 & 1.55 & 0.027 & 0.029 \\
\hline 8.02 & 0.99801 & 0.0512 & 0.0368 & 0.00560 & 0.00398 & 0.00403 & 0.0631 & 3.62 & 1.41 & 0.027 & 0.029 \\
\hline 9.02 & 0.99857 & 0.0411 & 0.0339 & 0.00419 & 0.00286 & 0.00346 & 0.0535 & 3.06 & 1.47 & 0.035 & 0.030 \\
\hline 10.00 & 0.99898 & 0.0331 & 0.0309 & 0.00325 & 0.00204 & 0.00304 & 0.0452 & 2.59 & 1.59 & 0.040 & 0.0 .28 \\
\hline 10.00 & 0.99894 & 0.0331 & 0.0318 & 0.00320 & 0.00212 & 0.00307 & 0.0460 & 2.64 & 1.51 & 0.040 & 0.028 \\
\hline \multicolumn{12}{|c|}{ Cable D - 1/16 1nch } \\
\hline 3.99 & 0.99121 & 0.1318 & 0.01012 & 0.0300 & 0.0175 & 0.00232 & 0.7323 & 7.60 & 1.71 & 0.009 & .0 .036 \\
\hline 4.00 & 0.99135 & 0.1304 & 0.01468 & 0.0298 & 0.0172 & 0.00338 & 0.1312 & 7.54 & 1.73 & 0.009 & 0.036 \\
\hline 4.00 & 0.99116 & 0.1323 & 0.01002 & 0.0298 & 0.0176 & 0.00228 & 0.1327 & 7.62 & 7.69 & 0.009 & 0.036 \\
\hline 5.00 & 0.99265 & 0.1205 & 0.01059 & 0.0191 & 0.0146 & 0.00169 & 0.1210 & 6.95 & 3.31 & 0.014 & 0.037 \\
\hline 5.01 & 0.99405 & 0.1066 & 0.0226 & 0.0187 & 0.0119 & 0.00399 & 0.1089 & 6.25 & 1.57 & 0.074 & 0.037 \\
\hline 6.00 & 0.99550 & 0.0872 & 0.0371 & 0.0123 & 0.00898 & 0.00525 & 0.0948 & 5.44 & 1.37 & 0.018 & 0.034 \\
\hline 6.00 & 0.99633 & 0.0784 & 0.0345 & 0.0122 & 0.00733 & 0.00541 & 0.0856 & 4.91 & 1.66 & 0.018 & 0.034 \\
\hline 6.00 & 0.99567 & 0.0864 & 0.0345 & 0.0124 & 0.00864 & 0.00498 & 0.0930 & 5.33 & 1.44 & 0.018 & 0.034 \\
\hline 6.99 & 0.99710 & 0.0669 & 0.0363 & 0.00867 & 0.00579 & 0.00472 & 0.0761 & 4.37 & 1.50 & 0.024 & 0.034 \\
\hline 7.02 & 0.99705 & 0.0655 & 0.0400 & 0.00834 & 0.00589 & 0.00511 & 0.0768 & 4.40 & 1.42 & 0.024 & 0.033 \\
\hline 7.98 & 0.99799 & 0.0531 & 0.0349 & 0.00634 & 0.00402 & 0.00418 & 0.0634 & 3.63 & 1.58 & 0.029 & 0.031 \\
\hline 8.01 & 0.99795 & 0.0511 & 0.0386 & 0.00600 & 0.00410 & 0.00454 & 0.0640 & 3.67 & 1.46 & 0.029 & 0.031 \\
\hline 8.98 & 0.99854 & 0.0437 & 0.0320 & 0.00484 & 0.00292 & 0.00355 & 0.0540 & 3.10 & 1.66 & 0.036 & 0.031 \\
\hline 9.00 & 0.99852 & 0.0410 & 0.0357 & 0.00449 & 0.00296 & 0.00391 & 0.0544 & 3.12 & 1.52 & 0.036 & 0.031 \\
\hline 9.98 & 0.99903 & 0.0331 & 0.0292 & 0.00365 & 0.00194 & 0.00322 & 0.0440 & 2.52 & 9.88 & 0.042 & 0.029 \\
\hline 10.00 & 0.99891 & 0.0339 & 0.0324 & 0.00350 & 0.00218 & 0.00335 & 0.0467 & 2.68 & 7.61 & 0.042 & 0.029 \\
\hline 17.00 & 0.99927 & 0.0282 & 0.0259 & 0.00295 & 0.00146 & 0.00271 & 0.0382 & 2.19 & 2.02 & 0.049 & 0.028 \\
\hline 12,00 & 0.99947 & 0.0212 & 0.0246 & 0.00218 & .0 .00106 & 0.00253 & 0.0326 & 1.87 & 2.06 & 0.057 & .0 .028 \\
\hline 13.00 & 0.99958 & 0.0208 & 0.0202 & 0.00205 & 0.00084 & 0.00199 & 0.0290 & 1.66 & 2.44 & 0.066 & 0.027 \\
\hline 33.80 & 0.99966 & 0.0173 & 0.0198 & 0.00168 & 0.00068 & 0.00192 & 0.0261 & 1.49 & 2.47 & 0.073 & 0.027 \\
\hline
\end{tabular}

*The values of \& were graphically extrapolated from values measured at other speeds. 
TABLE 2 (continued)

\begin{tabular}{|c|c|c|c|c|c|c|c|c|c|c|c|}
\hline $\begin{array}{l}\text { Speed } \\
\text { knots }\end{array}$ & $l$ & $m$ & $\mathrm{n}$ & $\mathrm{c}_{\mathrm{n}}$ & $\sin ^{2} \phi$ & $\mathrm{C}_{\mathrm{s}}$ & $\sin \phi$ & $\phi$ & $\frac{c_{n}}{\sin ^{2} \phi}$ & $8^{*}$ & $\mathrm{C}_{\mathrm{f}}$ \\
\hline \multicolumn{12}{|c|}{ Cable $E-1 / 8$ inch } \\
\hline 4.98 & 0.98978 & 0.1360 & 0.0432 & 0.0296 & 0.0203 & 0.00950 & 0.7426 & 8.20 & 1.46 & 0.026 & 0.033 \\
\hline 5.00 & 0.98945 & 0.1382 & 0.0434 & 0.0293 & 0.0210 & 0.00931 & 0.7449 & 8.33 & 1.40 & 0.027 & 0.034 \\
\hline 6.00 & 0.99276 & 0.1103 & 0.0475 & 0.0197 & 0.0744 & 0.00854 & 0.1201 & 6.90 & 1.37 & 0.034 & 0.031 \\
\hline 6.01 & 0.99297 & 0.1100 & 0.0438 & 0.0199 & 0.0740 & 0.00796 & 0.1184 & 6.80 & 1.42 & 0.034 & 0.031 \\
\hline 6.02 & 0.99295 & 0.7094 & 0.0455 & 0.0797 & 0.0141 & 0.00824 & 0.1185 & 6.81 & 1.40 & 0.034 & 0.031 \\
\hline 7.00 & 0.99461 & 0.0914 & 0.0487 & 0.0139 & 0.0708 & 0.00745 & 0.1037 & 5.95 & 1.29 & 0.042 & 0.029 \\
\hline 7.01 & 0.99479 & 0.0893 & 0.0493 & 0.0138 & 0.0104 & 0.00765 & 0.1020 & 5.85 & 1.33 & 0.042 & $0.02^{n}$ \\
\hline 7.03 & 0.99460 & 0.0918 & 0.0482 & 0.0138 & 0.0108 & 0.00730 & 0.1038 & $5: 96$ & 7.28 & 0.042 & 0.028 \\
\hline 8.01 & 0.99585 & 0.0731 & 0.0543 & 0.00969 & 0.00828 & 0.00723 & 0.0930 & 5.22 & 1.17 & 0.051 & 0.027 \\
\hline 8.02 & 0.99560 & 0.0749 & 0.0564 & 0.00962 & 0.00878 & 0.00727 & 0.0937 & 5.38 & 1.10 & 0.051 & 0.027 \\
\hline 8.03 & 0.99549 & 0.0772 & 0.0552 & 0.00976 & 0.00900 & 0.00701 & 0.0949 & 5.44 & 1.08 & 0.051 & 0.027 \\
\hline 8.95 & 0.99710 & 0.0547 & 0.0530 & 0.00695 & 0.00579 & 0.00676 & 0.0761 & 4.37 & 1.20 & 0.060 & 0.026 \\
\hline 9.00 & 0.99696 & 0.0545 & 0.0557 & 0.00669 & 0.00607 & 0.00686 & 0.0779 & 4.47 & 1.10 & 0.061 & 0.026 \\
\hline 9.02 & 0.99692 & 0.0565 & 0.0544 & 0.00686 & 0.00615 & 0.00663 & 0.0784 & 4.50 & 1.12 & 0.061 & 0.026 \\
\hline 9.98 & 0.99804 & 0.0368 & 0.0504 & 0.00458 & 0.00392 & 0.00628 & 0.0626 & 3.59 & 1.17 & 0.071 & 0.325 \\
\hline 10.00 & 0.99787 & 0.0400 & 0.0513 & 0.00476 & 0.00426 & 0.00612 & 0.0652 & 3.74 & 1.12 & 0.071 & 0.024 \\
\hline 10.01 & 0.99793 & 0.0402 & 0.0502 & 0.00484 & 0.00474 & 0.00606 & 0.0643 & 3.69 & 1.17 & 0.071 & 0.024 \\
\hline 10.92 & 0.99861 & 0.0277 & 0.0448 & 0.00342 & 0.00278 & 0.00554 & 0.0527 & 3.02 & 1.23 & 0.081 & 0.024 \\
\hline 10.95 & 0.99855 & 0.0302 & 0.0445 & 0.00363 & 0.00290 & 0.00536 & 0.0538 & 3.09 & 1.25 & 0.082 & 0.024 \\
\hline 17.93 & 0.99897 & 0.0223 & 0.0396 & 0.00268 & 0.00206 & 0.00476 & 0.0454 & 2.60 & 1.30 & 0.093 & 0.023 \\
\hline 11.93 & 0.99892 & 0.0253 & 0.0391 & 0.00297 & 0.00216 & 0.00459 & 0.0465 & 2.66 & 1.38 & 0.093 & 0.023 \\
\hline 12.95 & 0.99912 & 0.0238 & 0.0345 & 0.00263 & 0.00176 & 0.00382 & 0.0419 & 2.40 & 1.49 & 0.106 & 0.022 \\
\hline 12.98 & 0.99917 & 0.0184 & 0.0362 & 0.00208 & 0.00166 & 0.00410 & 0.0407 & 2.34 & 1.25 & 0.106 & 0.022 \\
\hline 13.93 & 0.99929 & 0.0215 & 0.0311 & 0.00228 & 0.00742 & 0.00330 & 0.0377 & 2.16 & 1.61 & 0.119 & 0.021 \\
\hline 13.93 & 0.99931 & 0.0191 & 0.0317 & 0.00206 & 0.00138 & 0.00347 & 0.0372 & 2.13 & 1.49 & 0.119 & 0.021 \\
\hline 14.96 & 0.99941 & 0.0195 & 0.0285 & 0.00197 & 0.00118 & 0.00288 & 0.0344 & 1.97 & 1.67 & 0.133 & 0.021 \\
\hline 14.96 & 0.99945 & 0.0173 & 0.0284 & $0.0018 ?$ & 0.00110 & 0.20297 & 0.0332 & 1.90 & 1.65 & 0.133 & 0.021 \\
\hline 15.97 & 0.99951 & 0.0171 & 0.0266 & 0.00166 & 0.00098 & 0.00259 & 0.0313 & 1.79 & 1.69 & 0.148 & 0.020 \\
\hline 15.99 & 0.99954 & 0.0741 & 0.0267 & 0.00141 & 0.00092 & 0.00268 & 0.0303 & 1.74 & 1.53 & 0.141 & 0.019 \\
\hline \multicolumn{12}{|c|}{ Cable F - $1 / 8$ 1nch } \\
\hline 5.00 & 0.98843 & 0.1392 & 0.0600 & 0.0315 & 0.0230 & 0.0137 & 0.1517 & 8.72 & 1.37 & 0.027 & 0.033 \\
\hline 5.01 & 0.98799 & 0.1443 & 0.0553 & 0.0378 & 0.0239 & 0.0724 & 0.1545 & 8.89 & 1.33 & 0.027 & 0.033 \\
\hline 5.02 & 0.98893 & 0.1373 & 0.0561 & 0.0315 & 0.0220 & 0.0130 & 0.7484 & 8.53 & 1.43 & 0.027 & 0.033 \\
\hline 5.93 & 0.99246 & 0.1089 & 0.0561 & 0.0218 & 0.0150 & 0.0113 & 0.1226 & 7.04 & 1.45 & 0.034 & 0.031 \\
\hline 5.99 & 0.99234 & 0.1060 & 0.0635 & 0.0205 & 0.0153 & 0.0124 & 0.1235 & 7.10 & 1.34 & 0.034 & 0.031 \\
\hline 6.02 & 0.99240 & 0.1063 & 0.0625 & 0.0205 & 0.0151 & 0.0122 & 0.1230 & 7.07 & 1.36 & 0.034 & 0.030 \\
\hline 7.00 & 0.99451 & 0.0814 & 0.0656 & 0.0137 & 0.0110 & 0.0111 & 0.1046 & 6.01 & 1.25 & 0.041 & 0.028 \\
\hline 7.03 & 0.99447 & 0.0799 & 0.0681 & 0.0133 & 0.0110 & 0.0174 & 0.1050 & 6.03 & 1.21 & 0.041 & 0.028 \\
\hline 7.99 & 0.99583 & 0.0596 & 0.0692 & 0.00885 & 0.00832 & 0.0103 & 0.0912 & 5.23 & 1.06 & 0.049 & 0.026 \\
\hline 8.00 & 0.99571 & 0.0541 & 0.0751 & 0.00790 & 0.00856 & 0.0110 & 0.0925 & 5.31 & 0.92 & 0.049 & 0.026 \\
\hline 8.02 & 0.99573 & 0.0544 & 0.0746 & 0.00792 & 0.00852 & 0.0109 & 0.0923 & 5.30 & 0.93 & 0.049 & 0.026 \\
\hline 8.99 & 0.99747 & 0.0364 & 0.0611 & 0.00548 & 0.00505 & 0.0092 & 0.0711 & 4.08 & 1.09 & 0.058 & 0.025 \\
\hline 9.00 & 0.99733 & 0.0339 & 0.0647 & 0.00496 & 0.00533 & 0.0095 & 0.0730 & 4.19 & 0.93 & 0.058 & 0.025 \\
\hline 9.01 & 0.99744 & 0.0336 & 0.0631 & 0.00501 & 0.00511 & 0.0094 & 0.0715 & 4.10 & 0.98 & 0.058 & 0.025 \\
\hline 9.97 & 0.99831 & 0.0219 & 0.0540 & 0.00329 & 0.00338 & 0.0081 & 0.0581 & 3.33 & 0.97 & 0.068 & 0.024 \\
\hline 9.98 & 0.99859 & 0.0256 & 0.0464 & 0.00420 & 0.00282 & 0.0076 & 0.0531 & 3.04 & 1.49 & 0.068 & 0.024 \\
\hline 17.00 & 0.99902 & 0.0143 & 0.0420 & 0.00231 & 0.00196 & 0.0068 & 0.0443 & 2.54 & 1.18 & 0.079 & 0.023 \\
\hline 12.00 & 0.99924 & 0.0119 & 0.0369 & 0.00184 & 0.00152 & 0.0057 & 0.0390 & 2.23 & 1.21 & 0.091 & 0.022 \\
\hline 12.00 & 0.99924 & 0.0107 & 0.0371 & 0.00165 & 0.00152 & 0.0057 & 0.0390 & 2.23 & 1.09 & 0.091 & 0.022 \\
\hline 13.00 & 0.99943 & 0.0087 & 0.0329 & 0.00132 & 0.00114 & 0.0050 & 0.0338 & 1.94 & 1.16 & 0.104 & 0.021 \\
\hline 14.00 & 0.99955 & 0.0075 & 0.0289 & 0.00131 & 0.00090 & 0.0043 & 0.0300 & 1.72 & 1.23 & 0.118 & 0.021 \\
\hline 14.96 & 0.99961 & 0.0078 & 0.0269 & 0.00708 & 0.00078 & 0.0037 & 0.0279 & 1.60 & 1.38 & 0.132 & 0.021 \\
\hline 15.95 & 0.99967 & 0.0076 & 0.0247 & 0.00101 & 0.00066 & 0.0033 & 0.0257 & 1.47 & 1.53 & 0.148 & 0.020 \\
\hline
\end{tabular}


TABLE 2 (continued)

\begin{tabular}{|c|c|c|c|c|c|c|c|c|c|c|c|}
\hline $\begin{array}{l}\text { Speed } \\
\text { knots }\end{array}$ & $l$ & $m$ & $n$ & $\mathrm{c}_{\mathrm{n}}$ & $\sin ^{2} \phi$ & $\mathrm{c}_{\mathrm{s}}$ & $\sin \phi$ & $\phi$ & $\frac{c^{n}}{\sin ^{2} \phi}$ & $\delta^{*}$ & $c_{f}$ \\
\hline \multicolumn{12}{|c|}{ Cable $G-1 / 8$ Inch } \\
\hline 5.00 & 0.98742 & 0.1399 & 0.0737 & 0.0326 & 0.0250 & 0.0174 & 0.1581 & 9.10 & 1.30 & 0.029 & 0.036 \\
\hline 5.00 & 0.98707 & 0.1408 & 0.0766 & 0.0324 & 0.0257 & 0.0179 & 0.1603 & 9.22 & 1.26 & 0.029 & 0.036 \\
\hline 6.00 & 0.99222 & 0.1004 & 0.0736 & 0.0208 & 0.0155 & 0.0153 & 0.1245 & 7.15 & 1.34 & 0.034 & 0.031 \\
\hline 6.00 & 0.99194 & 0.1025 & 0.0746 & 0.0208 & 0.0161 & 0.0153 & 0.1267 & 7.28 & 1.29 & 0.034 & 0.031 \\
\hline 6.02 & 0.99165 & 0.1066 & 0.0727 & 0.0211 & 0.0766 & 0.0145 & 0.3290 & 7.41 & 1.27 & 0.034 & 0.030 \\
\hline 7.00 & 0.99427 & 0.0735 & 0.0776 & 0.0130 & 0.0174 & 0.0138 & 0.1069 & 6.14 & 1.14 & 0.041 & 0.028 \\
\hline 7.00 & 0.99423 & 0.0759 & 0.0756 & 0.0134 & 0.0115 & 0.0134 & 0.7073 & 6.16 & 1.17 & 0.041 & 0.028 \\
\hline 7.02 & 0.99429 & 0.0746 & 0.0763 & 0.0132 & 0.0114 & 0.0136 & 0.1067 & 6.13 & 1.16 & 0.041 & 0.028 \\
\hline 7.98 & 0.99632 & 0.0446 & 0.0731 & 0.0076 & 0.00735 & 0.0125 & 0.0857 & 4.92 & 1.03 & 0.049 & 0.026 \\
\hline 7.99 & 0.99633 & 0.0435 & 0.0737 & 0.0074 & 0.00733 & 0.0126 & 0.0856 & 4.91 & 1.01 & 0.049 & 0.026 \\
\hline 8.02 & 0.99626 & 0.0440 & 0.0744 & 0.0074 & 0.00747 & 0.0125 & 0.0864 & 4.96 & 0.99 & 0.050 & 0.027 \\
\hline 8.98 & 0.99804 & 0.0233 & 0.0578 & 0.0043 & 0.00392 & 0.0107 & 0.0626 & 3.59 & 1.10 & 0.058 & 0.025 \\
\hline 9.00 & 0.99806 & 0.0231 & 0.0577 & 0.0043 & 0.00388 & 0.0107 & 0.0623 & 3.57 & 1.11 & 0.059 & 0.025 \\
\hline 9.02 & 0.99799 & 0.0259 & 0.0577 & 0.0047 & 0.00402 & 0.0104 & 0.0634 & 3.63 & 1.17 & 0.059 & 0.025 \\
\hline 9.97 & 0.99888 & 0.0140 & 0.0451 & 0.0028 & 0.00224 & 0.0090 & 0.0473 & 2.71 & 1.25 & 0.069 & 0.024 \\
\hline 9.98 & 0.99877 & 0.0108 & 0.0484 & 0.0020 & 0.00246 & 0.0092 & 0.0496 & 2.84 & 0.81 & 0.069 & 0.024 \\
\hline 10.00 & 0.99880 & 0.0133 & 0.0476 & 0.0025 & 0.00240 & 0.0091 & 0.0490 & 2.81 & 1.04 & 0.069 & 0.024 \\
\hline 10.00 & 0.99877 & 0.0117 & 0.0481 & 0.0022 & .0 .00246 & 0.0091 & 0.0496 & 2.84 & 0.89 & 0.069 & 0.024 \\
\hline 10.93 & 0.99917 & 0.0073 & 0.0401 & 0.0014 & 0.00166 & 0.0077 & 0.0407 & 2.34 & 0.84 & 0.081 & 0.024 \\
\hline 11.93 & 0.99943 & 0.0065 & 0.0331 & 0.0013 & 0.00114 & 0.0064 & 0.0338 & 1.94 & 1.14 & 0.093 & 0.023 \\
\hline 11.96 & 0.99941 & 0.0062 & 0.0338 & 0.0012 & 0.00718 & 0.0064 & 0.0343 & 1.97 & 1.02 & 0.093 & 0.023 \\
\hline 12.91 & 0.99954 & 0.0048 & 0.0299 & 0.0009 & 0.00092 & 0.0055 & 0.0303 & 1.74 & 0.98 & 0.106 & 0.022 \\
\hline 12.93 & 0.99957 & 0.0073 & 0.0286 & 0.0014 & 0.00086 & 0.0055 & 0.0293 & 1.68 & 1.63 & 0.107 & 0.022 \\
\hline 13.93 & 0.99964 & 0.0050 & 0.0262 & 0.0009 & 0.00072 & 0.0047 & 0.0268 & 1.54 & 1.25 & 0.121 & 0.022 \\
\hline 13.95 & 0.99965 & 0.0063 & 0.0255 & 0.0011 & 0.00070 & 0.0046 & 0.0265 & 1.51 & 1.57 & 0.121 & 0.022 \\
\hline 14.90 & 0.99970 & 0.0050 & 0.0238 & 0.0009 & 0.00060 & 0.0041 & 0.0245 & 1.40 & 1.50 & 0.136 & 0.021 \\
\hline 15.00 & 0.99971 & 0.0062 & 0.0233 & 0.0011 & 0.00058 & 0.0040 & 0.0241 & 1.38 & 1.90 & 0.137 & 0.021 \\
\hline 15.97 & 0.99972 & 0.0038 & 0.0232 & 0.0006 & 0.00056 & 0.0036 & 0.0237 & 1.36 & 1.07 & 0.152 & 0.027 \\
\hline 15.98 & 0.99975 & 0.0072 & 0.0208 & 0.0012 & 0.00050 & 0.0034 & 0.0224 & 1.28 & 2.40 & 0.153 & 0.027 \\
\hline \multicolumn{12}{|c|}{ Cable $\mathrm{H}-70$ inch $\mathrm{y} / \mathrm{H}$} \\
\hline 7.00 & & 0.1070 & 0.0902 & 0.0239 & 0.0196 & 0.0204 & 0.1400 & 8.05 & 1.22 & 0.091 & 0.029 \\
\hline 7.98 & 0.99252 & 0.0974 & 0.0736 & 0.0193 & 0.0149 & 0.0147 & 0.1221 & 7.01 & 1.30 & 0.106 & 0.027 \\
\hline 8.00 & 0.99274 & 0.0889 & 0.0811 & 0.0178 & 0.0145 & 0.0163 & 0.1203 & 6.91 & 1.23 & 0.106 & 0.027 \\
\hline 8.95 & 0.99448 & 0.0778 & 0.0705 & 0.0143 & 0.0110 & 0.0130 & 0.1049 & 6.02 & 1.30 & 0.123 & 0.025 \\
\hline 8.98 & 0.99411 & 0.0791 & 0.0740 & 0.0139 & 0.0117 & 0.0131 & 0.1084 & 6.22 & 1.19 & 0.123 & 0.025 \\
\hline 9.98 & 0.99553 & 0.0650 & 0.0686 & 0.0107 & 0.00892 & 0.0113 & 0.0945 & 5.42 & 1.20 & 0.141 & 0.024 \\
\hline 10.00 & 0.99567 & 0.0652 & 0.0663 & 0.0108 & 0.00864 & 0.0110 & 0.0930 & 5.33 & 1.25 & 0.141 & 0.024 \\
\hline 10.00 & 0.99611 & 0.0594 & 0.0650 & 0.0104 & 0.00777 & 0.0114 & 0.0881 & 5.06 & 1.34 & 0.141 & 0.024 \\
\hline 10.00 & 0.99548 & 0.0700 & 0.0643 & 0.0114 & 0.00902 & 0.0105 & 0.0950 & 5.45 & 1.26 & 0.141 & 0.024 \\
\hline 10.95 & 0.99701 & 0.0506 & 0.0586 & 0.00843 & 0.00597 & 0.00980 & 0.0773 & 4.43 & 1.41 & 0.760 & 0.023 \\
\hline 10.97 & 0.99664 & 0.0538 & 0.0618 & 0.00843 & 0.00671 & 0.00972 & 0.0819 & 4.70 & 1.26 & 0.160 & 0.023 \\
\hline 17.00 & 0.99653 & 0.0539 & 0.0635 & 0.00827 & 0.00693 & 0.00977 & 0.0832 & 4.77 & 1.19 & 0.161 & 0.023 \\
\hline 17.96 & 0.99739 & 0.0448 & 0.0566 & 0.00670 & 0.00521 & 0.00849 & 0.0722 & 4.74 & 1.29 & 0.183 & 0.022 \\
\hline 12.00 & 0.99768 & 0.0413 & 0.0541 & 0.00651 & 0.00464 & 0.00855 & 0.0681 & 3.90 & 1.40 & 0.193 & 0.023 \\
\hline 12.00 & 0.99727 & 0.0479 & 0.0563 & 0.00696 & 0.00545 & 0.00821 & 0.0738 & 4.23 & 1.28 & 0.184 & 0.022 \\
\hline 12.95 & 0.99792 & 0.0331 & 0.0552 & 0.00473 & 0.00416 & 0.00791 & 0.0645 & 3.70 & 1.14 & 0.208 & 0.021 \\
\hline 13.00 & 0.99789 & 0.0417 & 0.0499 & 0.00588 & 0.00422 & 0.00705 & 0.0649 & 3.72 & 1.39 & 0.209 & 0.021 \\
\hline 13.92 & 0.99867 & 0.0271 & 0.0440 & 0.00479 & 0.00266 & 0.00682 & 0.0516 & 2.96 & 1.58 & 0.232 & 0.021 \\
\hline 13.95 & 0.99833 & 0.0351 & 0.0457 & 0.00483 & 0.00334 & 0.00629 & 0.0578 & 3.31 & 1.45 & 0.233 & 0.021 \\
\hline 13.96 & 0.99853 & 0.0287 & 0.0463 & 0.00420 & 0.00294 & 0.00679 & 0.0542 & 3.11 & 1.43 & 0.233 & 0.021 \\
\hline 14.00 & 0.99824 & 0.0371 & 0.0461 & 0.00494 & 0.00352 & 0.00615 & 0.0593 & 3.40 & 1.40 & 0.244 & 0.021 \\
\hline 14.80 & 0.99892 & 0.0202 & 0.0420 & 0.00307 & 0.00216 & 0.00639 & 0.0465 & 2.66 & 1.42 & 0.253 & 0.020 \\
\hline 15.00 & 0.99861 & 0.0286 & 0.0443 & 0.00373 & 0.00278 & 0.00579 & 0.0527 & 3.02 & 1.34 & 0.264 & 0.020 \\
\hline 15.91 & 0.99912 & 0.0189 & 0.0376 & 0.00276 & 0.00176 & 0.00549 & 0.0479 & 2.40 & 1.57 & 0.290 & 0.020 \\
\hline 15.97 & 0.99899 & 0.0217 & 0.0392 & 0.00293 & 0.00202 & 0.00530 & 0.0449 & 2.58 & 1.45 & 0.292 & 0.020 \\
\hline 16.00 & 0.99886 & 0.0241 & 0.0413 & 0.00305 & 0.00228 & 0.00524 & 0.0477 & 2.74 & 1.34 & 0.293 & 0.020 \\
\hline
\end{tabular}


the experimental arrangement could introduce a constant source of error in the measurement of the cable angles. A small inconsistency in the geometry was discovered in reviewing the arrangement of the experiment. Although this error was corrected the possibility of a small systematic error in the measurement of the cable directions cannot be entirely disregarded.

TABLE 3 - Average Values of $\mathrm{C}_{\mathrm{r}}$

\begin{tabular}{|c|c|c|}
\hline Cable & $\begin{array}{c}\text { Diameter in } \\
\text { inches }\end{array}$ & $C_{r}$ \\
\hline A & $1 / 16$ & 1.82 \\
B & $1 / 16$ & 1.57 \\
C & $1 / 16$ & 1.47 \\
D & $1 / 16$ & 1.71 \\
E & $1 / 8$ & 1.34 \\
F & $1 / 8$ & 1.21 \\
G & $1 / 8$ & 1.23 \\
H & $1 / 4$ & 1.33 \\
\hline
\end{tabular}

The values of $\delta$ tabulated in Table 2 are also subject to some uncertainty because it could not be determined that any attempt had been made to correct the measurements of the drag forces acting on the cable for end and surface effects. However, inaccuracies in $\delta$ affect only the $C_{f}$ coefficient.

\section{DISCUSSION}

The plots of $\frac{\mathrm{C}_{n}}{\sin ^{2} \phi}$ against $\phi$ (Figure 3) show that the theory-that this value will not vary with $\phi$-is reasonably well fulfilled. There is a tendency for $\frac{C_{n}}{\sin ^{2} \phi}$ to be larger than the average value when $\phi$ lies between 1 and $21 / 2$ degrees, smaller than the average value in the range between $21 / 2$ degrees and 6 degrees and again larger than the average value in the range between 6 and 9 degrees. However, this deviation from the average does not support the postulated existence of a $\sin \phi$ term; i.e., the suggestion that $C_{n}$ may be written as $C_{n}=A \operatorname{Sin}_{n} \phi+B \sin ^{2} \phi$, where $A$ and $B$ are constants. This may be seen by plotting $\frac{\mathrm{C}_{n}}{\sin \phi}$ against $\sin \phi$. The failure of the strajght line fitted to such a plot to pass through the origin would indicate the existence of a sin $\phi$ term in the expression for $c_{n}$. Figure 5 represents a typical plot of $\frac{C_{n}}{\sin \phi}$ against $\phi$. It is seen that a straight line through the origin fits 

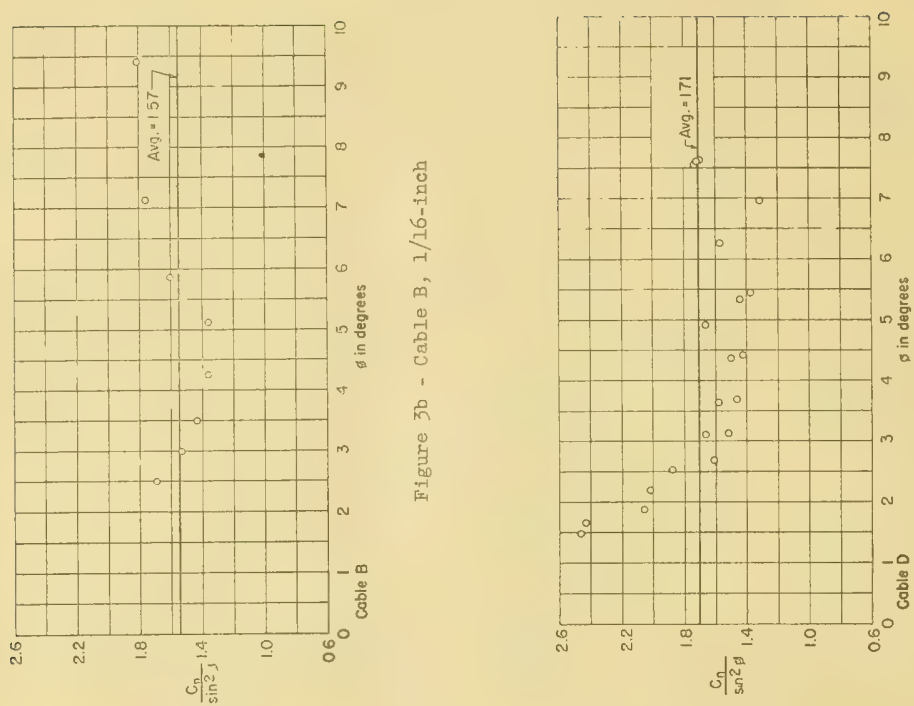

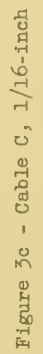
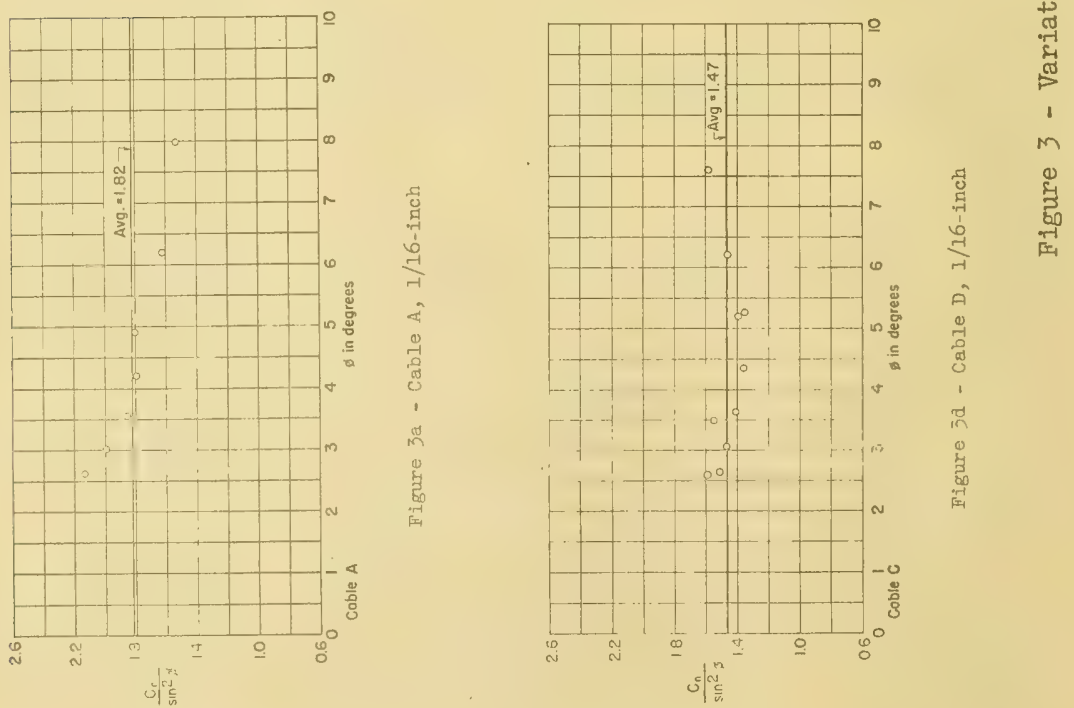

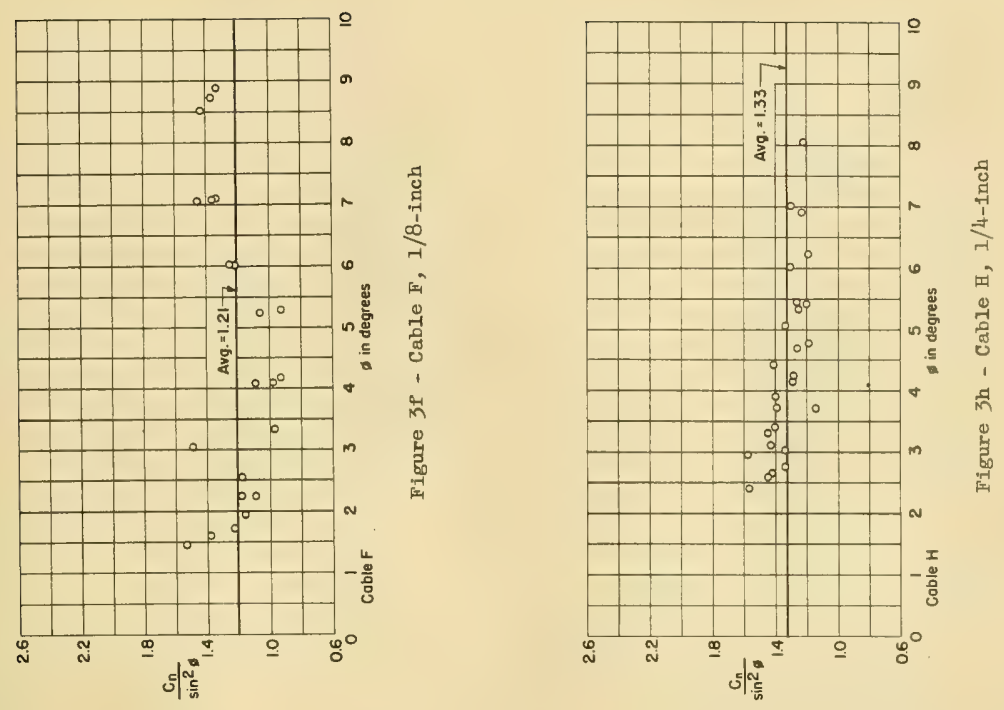

ह.
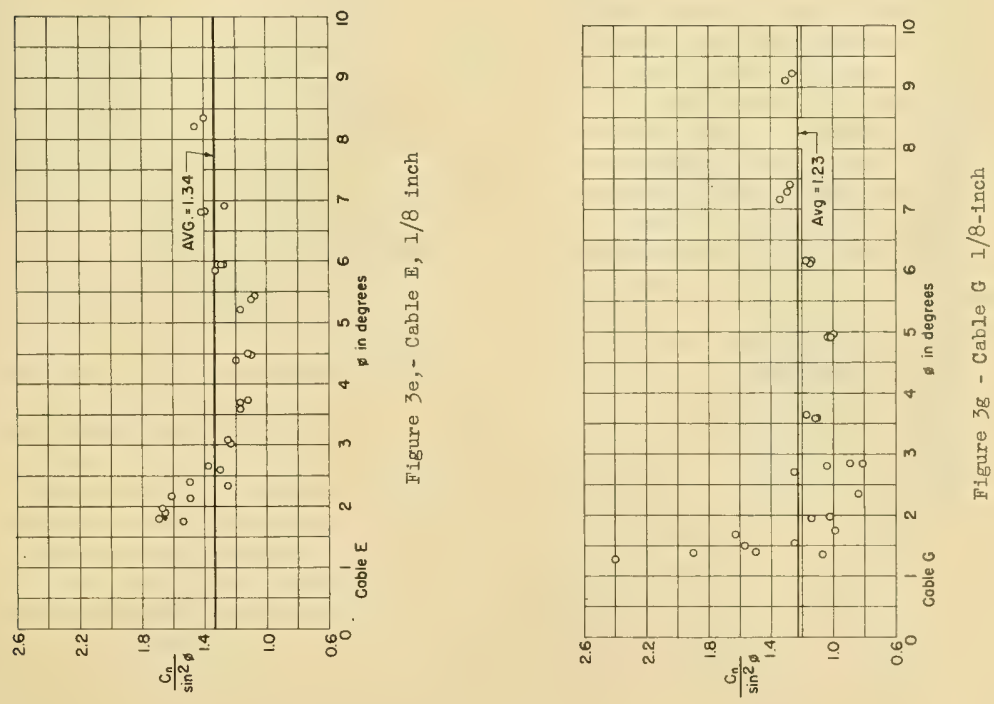

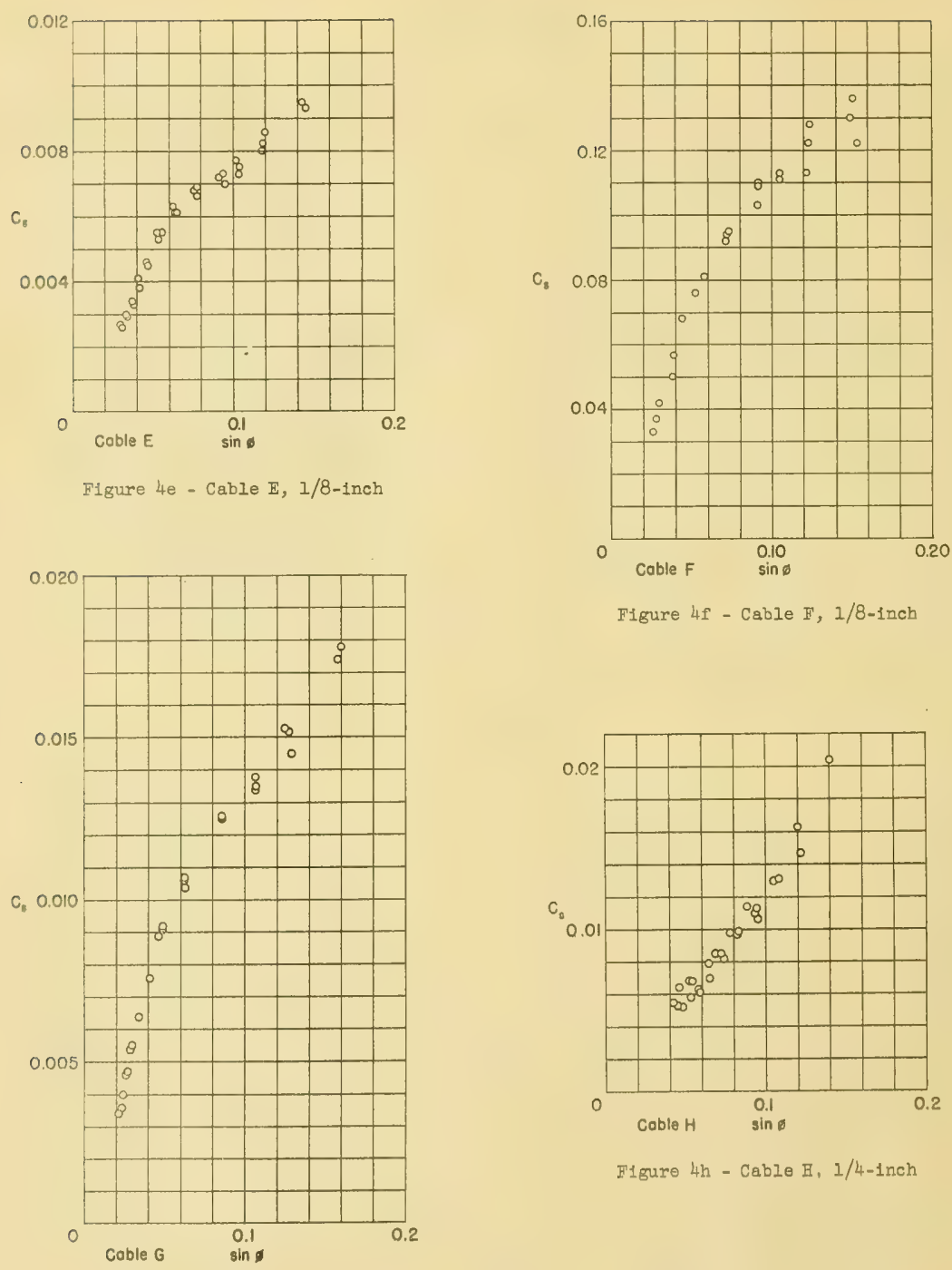

F1gure 4h - Cable H, 1/4-1nch

Figure $4 g$ - Cable $G, 1 / 8-1$ nch

Figure 4 - Variation of $C_{S}$ with $\sin \phi$ 


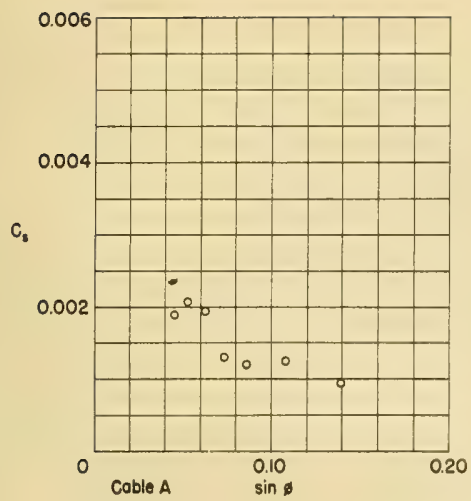

Figure 4a - Cable A, 1/16-1nch

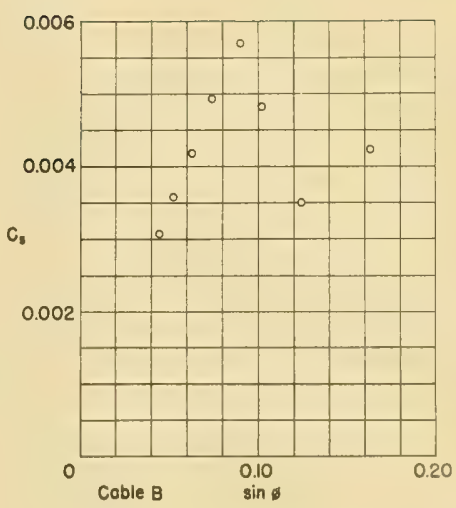

Figure 4b - Cable B, 1/16-1nch

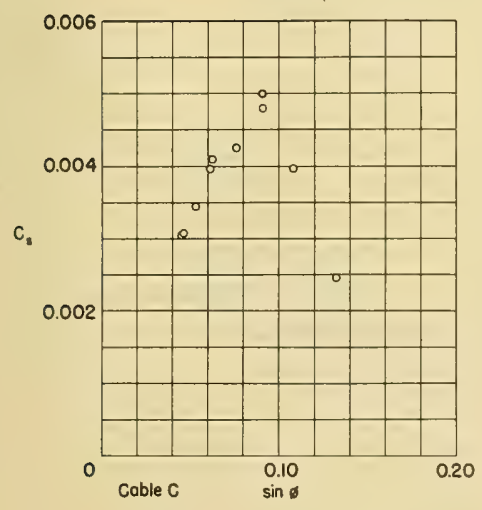

Figure 4c - Cable C, I/16-inch

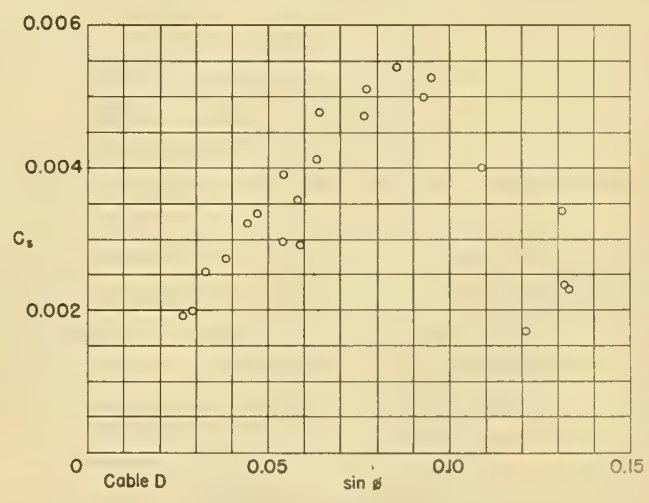

Figure 4d - Cable D, 1/16-inch

Figure 4 - Variation of $C_{S}$ with $\sin \phi$ 


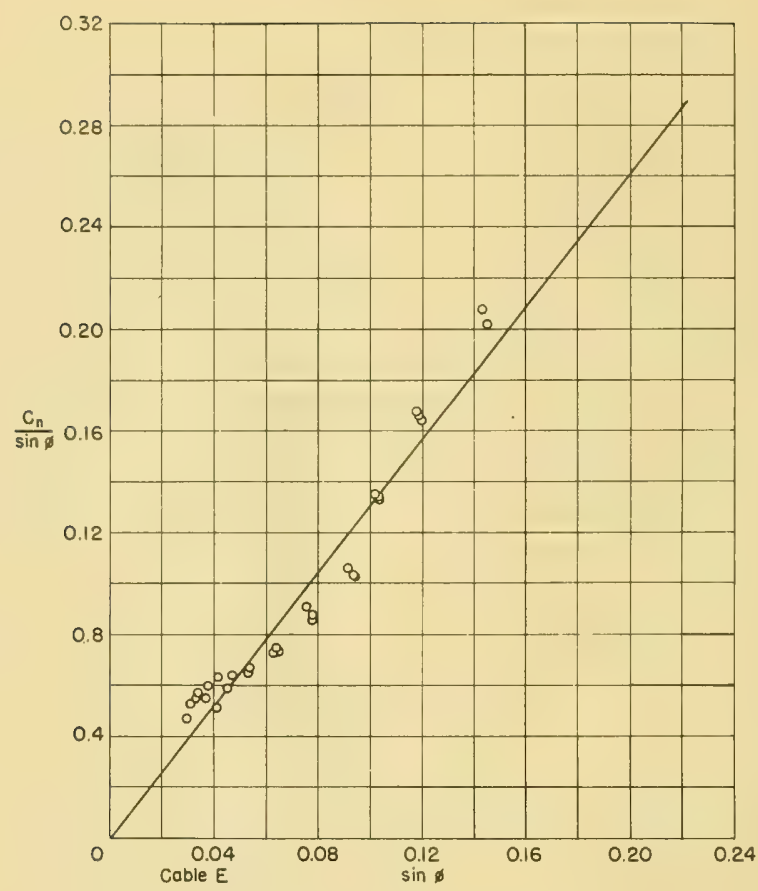

Figure 5 - Variation of $\frac{C_{n}}{\sin \phi}$ with $\sin \phi$

the data fairly well and no significant improvement of the fit can be made by not passing the straight line through the origin. Considerable improvement in the fit can be made only by use of a curvilinear representation.

It is believed that the postulation of the $\sin \phi$ term arose from the neglect of the side force and the yawing of the cable. When the cable is inclined at a small angle to the stream the side force will be oriented so as to have a large component upward. Hence the cable will tow closer to the surface of the water and the configuration of the cable in the vertical plane will indicate an apparent increase in the normal force.

It is hard to say how much of the deviation from the sine-squared law could be due to systematic error in the measurement of the cable angles. Some deviation from the sine-squared law is to be expected since this law is supported by theory only for true cylindrical forms. It is the departure of the stranded cable from true cylindrical form that is responsible for the existence of the side-force and it is not unreasonable to suppose that this departure from cylindrical form will also affect the normal force. 
From Figure 4 it is seen that the side-force increases linearly with $\sin \phi$ when $\phi$ is very small and in most cases reaches a maximum value within the range of $\phi$ investigated in the experiments. In other cases there is a leveling off that suggests that a maximum value is reached at larger values of $\phi$. The initial slope of the $\mathrm{C}_{s}$ curves and the position of the maximum vary with the size and the construction of the cable.

The speed of towing has a marked effect upon the coefficient of the tangential force, $\mathrm{C}_{f}$, and consequently the variation of $\mathrm{C}_{\mathrm{f}}$ with $\phi$ is difficult to determine from experiments of the type reported here. Although this coefficient is too small and too inaccurately measured to justify a detailed analysis, the results agree in a qualitative way with those obtained from other experiments. A commonly used estimate for $C_{f}$ for stranded cables is $C_{f}=0.02 C_{r}$. The values of $\mathrm{C}_{f}$ listed in Table 2 are of the correct order of magnitude (as given by this estimate). Also in agreement with other results, $\mathrm{C}_{f}$ decreases with increased towing speed and with increased cable diameter.

\section{CONCLUSIONS}

Because of the uncertainties regarding the data the conclusions reached must be of a somewhat tentative nature. However it is clear that the sine-squared law for the coefficient of the normal force $C_{n}$ holds fairly well for small inclinations of the cable to the stream and that there is no indication of a sine term in the expression for this coefficient. Interpretation of the deviations from this law should await confirmation of the results by additional experiments. At small angles the coefficient of the side force $\mathrm{C}_{\mathrm{S}}$ seems to vary linearly with the angle. At larger angles there is often a falling off which suggests a stalling phenomenon. The coefficient of the tangential force $C_{f}$ has not been measured very accurately but the results with respect to this coefficient agree at least in a qualitative way with the results of other experiments. 


